\title{
Tratamiento periodontal quirúrgico: Revisión. Conceptos. Consideraciones. Procedimientos. Técnicas
}

\author{
Periodontal surgical therapy: Review. Concepts. Considerations. \\ Procedures. Techniques
}

\author{
MATOS CRUZ R* \\ BASCONES-MARTÍNEZ A**
}

\begin{abstract}
Matos Cruz R, Bascones-Martínez A. Tratamiento periodontal quirúrgico: Revisión. Conceptos. Consideraciones. Procedimientos. Técnicas. Av Periodon Implantol. 201 1; 23, 3: 155-170.
\end{abstract}

\section{RESUIMEN}

El tratamiento global de pacientes con enfermedad periodontal se divide en tres fases diferentes que, con frecuencia, se superponen: fase de terapia causal o fase inicial y la fase correctiva o fase de soporte periodontal o de mantenimiento. Como la mayoría de las formas de enfermedad periodontal son trastornos relacionados con la placa bacteriana, el tratamiento periodontal quirúrgico está considerado como un auxiliar del tratamiento periodontal causal inicial. Así mismo, la decisión respecto a qué tipo de cirugía periodontal debe realizarse, cuántas localizaciones deben incluirse y en qué momento del tratamiento, se adopta tras haberse evaluado el efecto de las medidas iniciales relacionadas con la causa. El objetivo principal del tratamiento periodontal quirúrgico es la preservación a largo plazo del periodonto. La cirugía periodontal puede contribuir, a este propósito, creando accesibilidad para el raspado y alisado radicular correctos, realizados por el profesional y al restablecer una morfología gingival que facilita el autocontrol de placa por parte del paciente. Las diversas técnicas quirúrgicas desarrolladas a lo largo del tiempo deben evaluarse sobre la base de su potencial para facilitar la eliminación de los depósitos subgingivales, bien como facilitar el autocontrol de la placa y así mejorar la preservación a largo plazo del periodonto. En el presente artículo se pretende realizar una revisión de los fundamentos del tratamiento periodontal quirúrgico, conceptos y consideraciones, objetivos, indicaciones y contraindicaciones, procedimientos y factores que determinan la elección de una u otra técnica quirúrgica.

PALABRAS CLAVE: Cirugía periodontal, concepto, clasificación, indicaciones, contraindicaciones, técnicas.

\section{SUIMIMARY}

Periodontal treatment can be divided in three different phases most frequently superposed: causerelated or initial phase, corrective phase and supportive periodontal phase. Because the majority of these pathologies are related to plaque accumulation, periodontal surgical treatment might only be considered as an adjunct to cause-related periodontal therapy. The kind of surgery performed, the number of sites included and the moment at which it should performed is decided after evaluating for the initial cause-related therapy results. The ultimate objective of periodontal surgical treatment is the long term preservation of the periodontium. Periodontal surgery can contribute to this end creating accessibility for an adequate scaling and root planning therefore restoring the gingival morphology which facilitates the automatic plaque control of the patient. Developed surgical techniques must be evaluated on the basis of their potential to facilitate the elimination of subgingival deposits, as well as facilitate plaque control and thus improve the long term preservation of the periodontium. In the present article the authors review the basis of surgical periodontal treatment

Licenciada en Odontología. Alumna del Máster en Periodoncia e Implantología UCM.

Catedrático de Medicina Bucal y Periodoncia. Departamento de Estomatología III. Facultad de Odontología. Universidad Complutense de Madrid. 
as well as related concepts and considerations, objectives, indications and contraindications, procedures and factors that determine the selection of one or the other surgical technique.

KEYWORDS: Periodontal surgery, concept, classification, indications, contraindications, techniques.

Fecha de recepción: 17 de junio de 2009.

Fecha de aceptación: 23 de junio de 2009.

\section{INTRODUCCIÓN}

El tratamiento global de pacientes con enfermedad periodontal se divide en tres fases diferentes, que con frecuencia se superponen. La fase de terapia causal inicial va dirigida a controlar las caries y la gingivitis y tiene como objetivo detener la progresión de la destrucción de los tejidos periodontales. El raspado y alisado radicular es, en la mayoría de los casos, junto con instrucciones de higiene oral, el arma terapéutica utilizada. Tras la fase inicial de tratamiento se sigue la fase correctiva, dirigida a establecer la función y la estética. Tras la fase inicial y correctiva, los pacientes pasan a una fase de soporte periodontal o de mantenimiento caracterizada por la adopción de medidas destinadas a prevenir la recidiva de la caries y de la enfermedad periodontal.

Como la mayoría de las formas de enfermedad periodontal son trastornos relacionados con la placa bacteriana, el tratamiento periodontal quirúrgico está considerado como un auxiliar del tratamiento periodontal causal inicial. Así mismo, la decisión respecto a qué tipo de cirugía periodontal debe realizarse, cuántas localizaciones deben incluirse y en qué momento del tratamiento, se adopta tras haberse evaluado el efecto de las medidas iniciales relacionadas con la causa.

En general, el tiempo transcurrido entre la terminación de la fase terapéutica relacionada con la causa y la reevaluación periodontal varía, según la literatura, entre 1 y 6 meses (2). Éste es un régimen ventajoso. Una de las ventajas es que la eliminación del cálculo y de la placa bacteriana ha de eliminar o reducir de forma destacada el infiltrado celular inflamatorio en la encía (edema, hiperemia, baja consistencia de tejidos), hecho que posibilita la evaluación de los contornos gingivales y de la profundidad de bolsa "real". Además, la reducción de la inflamación gingival hace que los tejidos blandos sean más fibrosos y por ende más finos, lo cual facilita su manejo quirúrgico. También disminuye la propensión al sangrado, con lo que se simplifica la inspección del campo quirúrgico. En definitiva, permite la evaluación adecuada de la eficiencia de los autocuidados de higiene oral, de importan- cia decisiva para el pronóstico a largo plazo. La ineficiencia a menudo implica que ese paciente debe ser excluido del tratamiento quirúrgico.

Las técnicas periodontales quirúrgicas deben evaluarse sobre la base de su potencial para facilitar la eliminación de los depósitos subgingivales, bien como facilitar el autocontrol de la placa y así mejorar la preservación a largo plazo del periodonto (3). Las primeras técnicas quirúrgicas utilizadas en cirugía periodontal estaban descritas para tener acceso a las superficies radiculares y así poder desbridarlas adecuadamente. Ese acceso podía realizarse sin escisión de la bolsa de tejidos blandos o sin involucrar a los tejidos duros. Más tarde, se describieron procedimientos mediante las cuales no solo se trataban los tejidos blandos, pero también a los tejidos duros. De la simple gingivectomía pasó a realizarse una cirugía a colgajo que permitía exponer el hueso alveolar y a su vez dar a la zona intervenida un contorno fisiológico favorable a las medidas de higiene oral. A la vez que surgían nuevas técnicas, nuevos conceptos brotaban, como el de mantener el complejo mucogingival o la posibilidad de regeneración del aparato de inserción, ambos asociados a técnicas quirúrgicas elaboradas.

No existe una sola técnica quirúrgica estandarizada para todos los casos. Cada uno de los procedimientos quirúrgicos está diseñado para una situación específica o con un objetivo predeterminado. En cada caso se utilizan diferentes técnicas combinadas para cumplir con los objetivos globales del tratamiento quirúrgico periodontal. A lo largo de los años se describieron y utilizaron varias técnicas quirúrgicas diferentes entre sí. De interés histórico es la referencia a Robicsek (1884), pionero en la denominada gingivectomía. Este procedimiento quirúrgico buscaba la eliminación de la bolsa y se combinaba a menudo con el recontorneado de la encía para restaurar su forma fisiológica. Más tarde, Zentler (1918) describió el mismo procedimiento con una incisión festoneada, frente a la incisión recta preconizada por Robicsek. En ambos casos el resultado obtenido incluía la erradicación de la bolsa periodontal profundizada y una condición local que 
permitía conservar más fácilmente la higiene oral. La gingivectomía, tal y como se emplea hoy en día fue descrita por Goldman en 1951 y se describe a lo largo de esta revisión.

La cirugía a colgajo puede emplearse en todos los casos en que esté indicado el tratamiento quirúrgico. Una de las primeras descripciones detalladas del uso de un procedimiento con colgajo para la eliminación de bolsas fue publicada en el año 1918 por Leonard Widman. En su artículo "The operative treatment of pyorrhea alveolaris"Widman describió un diseño de un colgajo mucoperióstico con el propósito de eliminar el epitelio de la bolsa y el tejido conectivo inflamado, con lo cual se facilitaba la higienización óptima de las superficies radiculares.

Estas dos publicaciones son referencias históricas y las principales ventajas de un colgajo original de Widman frente a una gingivectomía consisten en la creación de menores molestias para el paciente (ya que la cicatrización ocurría por primera intención) y que era posible restablecer un contorno fisiológico correcto del hueso alveolar en localizaciones con defectos óseos angulares.

Muchos de los problemas técnicos que surgen durante una cirugía periodontal provienen de la dificultad de evaluar y diagnosticar, previo a la cirugía y con un $100 \%$ de certeza el grado y el tipo de destrucción ocurridos. Además, es frecuente la identificación intraquirúrgica de defectos antes no diagnosticados o de conformación más compleja que la prevista. Como regla general, deben preferirse las modalidades quirúrgicas de terapia que preserven o induzcan la formación de tejido periodontal a aquellas resectivas o eliminadoras de hueso.

En el presente artículo se pretende realizar una revisión de los fundamentos del tratamiento periodontal quirúrgico, conceptos y consideraciones, objetivos, indicaciones y contraindicaciones, procedimientos y factores que determinan la elección de una u otra técnica quirúrgica.

\section{TRATAIMIENTO PERIODONTAL QUIRÚRGICO: CONCEPTOSY CONSIDERACIONES}

\section{OBJETIVOS DEL TRATAIMIENTO PERIODONTAL QUIRÚRGICO}

Tradicionalmente uno de los principales objetivos del tratamiento periodontal era la eliminación de la bolsa periodontal, formada a consecuencia de la inflamación gingival y migración de la adherencia epitelial. El aumento de la profundidad de bolsa era la principal indicación para la cirugía periodontal. Tras la eliminación del componente inflamatorio provocado por la placa, lo que ocurría era la eliminación quirúrgica de la bolsa, un procedimiento que cumplía con dos propósitos: la reducción de la profundidad de bolsa o supresión de la bolsa y el aumento del acceso a la superficie radicular, de manera que se eliminen los factores irritativos y que proporcionen una anatomía adecuada a los autocuidados de higiene oral tras el período de cicatrización.

Aunque hoy en día este objetivo no pueda descartarse por completo, el concepto de eliminación de bolsas como principal objetivo del tratamiento periodontal quirúrgico dejó de ser inequívoco. Existen algunos estudios publicados en la literatura que, basados en el conocimiento actual de la biología del periodonto, en la patogenia de la enfermedad periodontal y en la cicatrización de los tejidos periodontales, nos ayudan a comprender el papel que desempeña la cirugía periodontal en la preservación de los dientes.

En relación con la variable clínica profundidad de bolsa (distancia desde el margen gingival hasta la base de la bolsa gingival, medida con una sonda periodontal graduada), hoy día se sabe que ésta sólo rara vez corresponde a la "verdadera" profundidad de bolsa (PB). Algunos estudios publicados en la década de 1970 demostraron que no siempre la punta de la sonda identifica el nivel más apical del epitelio dentogingival (4, $5)$, con lo que sería erróneo utilizar solamente este parámetro para decidir la indicación de un procedimiento quirúrgico. En un clásico de la literatura publicado en el año 1976, Listgarten determinó donde está situada la punta de la sonda durante los registros periodontales (4). El objetivo de este estudio (con un diseño transversal) fue determinar hasta donde penetraba la punta de la sonda periodontal cuando sondaba y si es era un método fiable para el diagnóstico rutinario de bolsas periodontales. En una muestra de 31 dientes unirradiculares en su mayoría e indicados para exodoncia, midió la PB (con una sonda periodontal Glickman N28, por mesial y distal de cada diente, desde un punto de referencia (el LAC o un surco hecho al lado del LAC) y calculó la media de las mediciones para cada uno de los lados. Tras la exodoncia de los dientes, con subsiguiente fijación y seccionamiento (con descalcificación y de manera que en cada sección se vea la marca apical (P) y el LAC o un surco 
hecho al lado del LAC), marcaban 4 zonas en cada diente: $\mathrm{P}$ o zona estimada donde se localiza la punta de la sonda (marca más apical desde el LAC); API o extensión apical de la placa; CJE o extensión coronal del epitelio de unión; CCT o extensión coronal del cemento. Las muestras en las que no se podría identificar 20 más muescas quedaron excluidas. Los resultados de esta investigación indicaron que no hubo DES entre los niveles de $P$ y $C C T$, usando la extensión apical de la placa o la extensión coronal del epitelio como punto de referencia. Además, 1,3 mm era la medida de adherencia del epitelio de unión (desde la porción más coronal hasta la porción más apical) y era una medida estable (Fig. 1). Se verificó que la punta de la sonda se para generalmente entre el epitelio de unión y la inserción del tejido conectivo en la raíz y puede interrumpirse dentro en el conectivo (Fig. 1). A pesar de las limitaciones de este estudio (como por ejemplo el hecho de que descalcifiquen los dientes experimentales con pierda de referencias anatómicas, o de que realicen histometría y, por ende, sólo mediciones lineales o que no incluyan la sonda en el corte histológico y que las mediciones puedan estar infraestimadas debido a que todos los dientes eran periodontales,

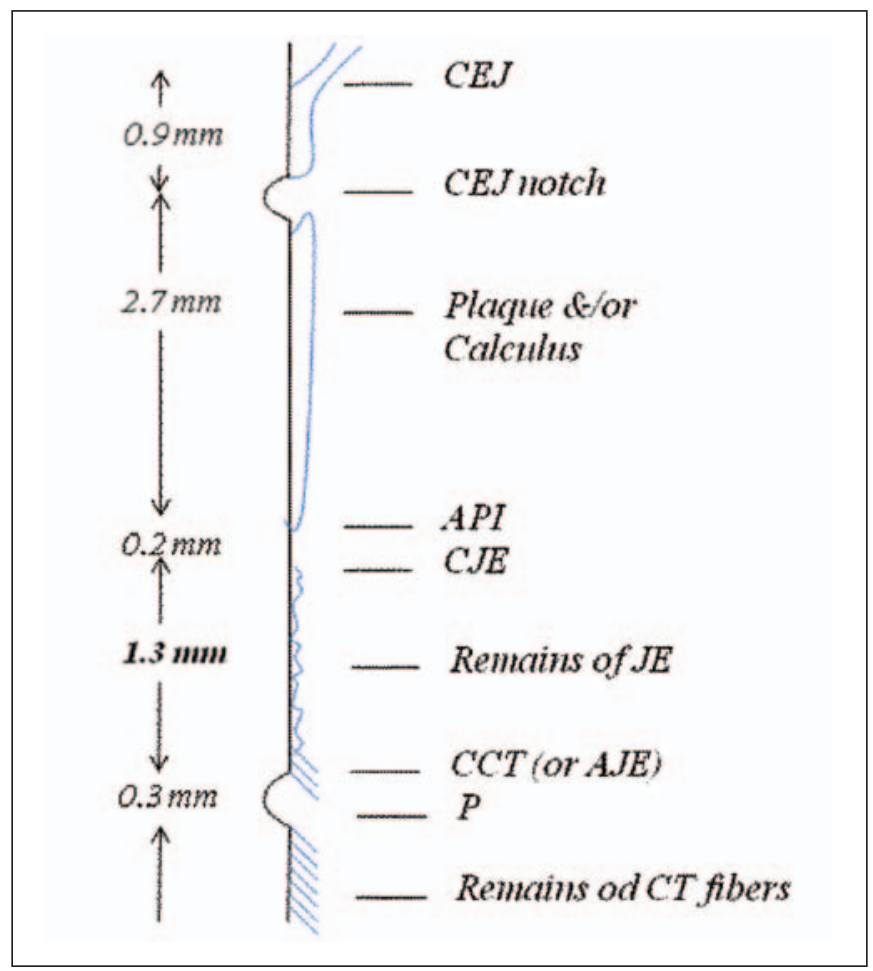

Fig. 1: Esquema representativo de los resultados obtenidos por Listgarten y cols. (1976): 1,3 mm es la medida de adherencia del epitelio de unión y es una medida estable (4). los resultados justifica la diferenciación entre surco histológico y surco clínico.

En otra publicación del año 1980 Listgarten y cols. enumeraron una variedad de factores que influyen en el resultado de una medición realizada con una sonda periodontal. Estos factores incluían el espesor de la sonda periodontal empleada, la mala posición de la sonda debida a características anatómicas (como por ejemplo el contorno de la superficie dentaria), la presión aplicada sobre el instrumento durante el sondaje y el grado de infiltrado celular inflamatorio en el tejido blando, acompañado por la pérdida de colágeno. Listgarten sugirió que debería realizarse una distinción entre la PB histológica y clínica, para diferenciar entre la profundidad del defecto anatómico real y la medición registrada por la sonda (6).

Además, no existe una correlación establecida entre la profundidad de sondaje y la presencia o ausencia de enfermedad activa, lo que significa que deben existir síntomas distintos del aumento de PB para justificar la terapia quirúrgica. Entre estos se pueden incluir la exudación y el sangrado (síntomas clínicos de inflamación), aberraciones de la morfología gingival, entre otros.

Axelsson y Lindhe realizaron un estudio en el año 1981 sobre el que también podemos basarnos para mejor comprender el papel que desempeña la cirugía periodontal en la preservación a largo plazo de los dientes. En esta publicación, los autores subrayan la importancia de unos correctos hábitos de higiene oral poniendo de manifiesto que el control de placa adecuado, mantenido por el paciente, constituye un factor decisivo para un buen pronóstico y debe tenerse en consideración antes de iniciar el tratamiento quirúrgico. Según estos autores, el éxito del tratamiento dependerá del mantenimiento de niveles de placa compatibles con la salud gingival, con lo que el control de placa adecuado se transforma en uno de los objetivos del tratamiento quirúrgico $(7,8)$.

Por todo lo que se ha expuesto, podemos concluir que el objetivo principal de la cirugía periodontal no es solo la eliminación de forma radical de la bolsa. Es contribuir a la preservación del periodonto a largo plazo. La cirugía periodontal puede contribuir, a este propósito, creando accesibilidad para el raspado y alisado radicular correctos, realizados por el profesional y restableciendo una morfología gingival que facilita el autocontrol de placa por parte del paciente. 


\section{INDICACIONES DEL TRATAMIENTO PERIODONTAL QUIRÚRGICO}

El tratamiento periodontal quirúrgico está indicado en situaciones que impidan el acceso para el raspado y alisado radicular, en impedimentos en el acceso para el correcto autocontrol de placa o en casos de múltiples sondajes residuales $\geq 6 \mathrm{~mm}$ en la reevaluación postratamiento no quirúrgico (9).

\section{Impedimentos en el acceso para el raspado y alisado radicular}

El RAR es un método terapéutico difícil y que exige algún entrenamiento de forma a poder ser realizado de forma correcta y con buenos resultados. Las dificultades para la realización de un desbridamiento correcto aumentan con la mayor profundidad de bolsa, con una mayor superficie dental, por la presencia de fisuras y concavidades radiculares, furcaciones y márgenes defectuosos de restauraciones dentales en el área subgingival.

Según algunos autores, si se utiliza una técnica correcta y unos instrumentos adecuados, casi siempre es posible raspar de forma adecuada las bolsas de hasta $5 \mathrm{~mm}$ de profundidad $(10,11)$. Este límite de $5 \mathrm{~mm}$ no debe ser tomado como regla de oro universal. La accesibilidad reducida y la presencia de uno o más de los impedimentos antes mencionados pueden obstaculizar el desbridamiento correcto de bolsas poco profundas, mientras que en localizaciones con buena accesibilidad y morfología radicular favorable, el desbridamiento correcto se puede efectuar en bolsas aún más profundas, tal y como señaló Anita Badersten en una series de estudios publicados sobre el efecto tratamiento periodontal no quirúrgico (12).

Cuando síntomas como el sangrado al sondaje suave en el área subgingival o inflamación visible persisten, debe sospecharse de la presencia de depósitos de cálculo. Si estos síntomas no remiten con la instrumentación repetida, es cuando es necesario el tratamiento quirúrgico, exponiendo así las superficies radiculares para una mejor higienización.

\section{Impedimentos en el acceso para el correcto autocontrol de placa}

A su vez, el nivel del control de placa que puede ser mantenido por el paciente viene determinado no solo por su interés y su destreza, sino también por la morfología del área dentogingival.

La responsabilidad del paciente en el programa de control de placa es también un aspecto crucial y el área dental situada hacia coronal del margen gingival y a nivel de la entrada en el surco gingival debe ser objeto de mucho esfuerzo higiénico por parte del paciente.

La hiperplasia gingival o la presencia de márgenes aberrantes de restauraciones dentarias, con un deficiente ajuste marginal pueden comprometer la eliminación de placa. El tratamiento periodontal por parte de un profesional permite un adecuado autocontrol de placa, de forma eficiente. Tras terminar el tratamiento deben haberse alcanzado ciertos objetivos, que originan las diferentes indicaciones para la cirugía periodontal (Fig. 2).

\section{Múltiples sondajes residuales $\geq 6 \mathrm{~mm}$ en la reevaluación postratamiento no quirúrgico}

Algunos estudios tratan de establecer una relación entre variables clínicas y un posterior deterioro pe-

\section{OBJETIVOS}

- Ausencia de depósitos subgingivales o supragingivales.

- Ausencia de bolsas patológicas (sin sangrado al sondaje).

- Ausencia de aberraciones retentivas de placa en la morfología gingival.

- Ausencia de partes de restauraciones en relación con el margen que sean capaces de retener placa.

\section{INDICACIONES}

- Accesibilidad para RAR correcto.

- Creación de una morfología del área dentogingival que favorezca el control de placa.

- Reducción de la PB.

- Corrección de aberraciones gingivales notorias.

- Desplazamiento del margen gingival hasta una posición apical relativamente a restauraciones retentivas de placa.

- Facilitar la terapia restauradora correcta.

Fig. 2: Objetivos e indicaciones del tratamiento periodontal quirúrgico. 
riodontal a "nivel paciente" y a "nivel localización". A nivel paciente el grado de destrucción periodontal en el examen basal parece ser el mejor indicador de pérdida futura de inserción en el caso de pacientes no tratados. La placa y el sangrado de boca completa en basal también han mostrado alguna asociación.

Cuando los pacientes reciben tratamiento estas variables pierden la poca predictibilidad que tenían. Claffey y cols. estudiaron la incidencia de pérdida de inserción en durante un periodo de 42 meses post-tratamiento causal inicial y la relacionaron con variables clínicas a nivel de localización. Estos resultados daban una idea del valor predictivo que pueden tener los distintos parámetros clínicos (placa, sangrado, supuración, etc).

Claffey y Egelberg (1995) realizaron un estudio que consistió en una serie de casos cuyo objetivo era analizar la asociación entre variables clínicas y pérdida de inserción, a nivel del paciente y a nivel de la localización (9). Para ello seleccionaron a 16 pacientes (edades comprendidas entre los 35-65 años), sin tratamiento periodontal previo (5 años antes) con diagnóstico de periodontitis generalizada. Todos menos uno presentaban también al menos 2 molares con furcas detectables clínicamente. Se incluyeron en el estudio todos los dientes excepto terceros molares y aquellos con pérdida de inserción hasta el ápice. El número de dientes remanentes era de 21,4 de media con un rango amplio (8-28). En cuanto a consumo de tabaco el grupo era también muy heterogéneo: 4 fumadores, $3 \mathrm{ex}$ fumadores y 9 no fumadores. Seis pacientes recibían medicación por diversas enfermedades sistémicas (2, por hipotiroidismo; 2, por hipertensión; 1, por glaucoma y otro, por IAM). Las variables clínicas (placa, PS, NIC) fueron monitorizadas en basal y cada 3 meses, por 3 examinadores. Dos, durante la primera mitad del estudio y otro, calibrado durante el resto del estudio. Para la identificación de localizaciones con pérdida de inserción utilizaron 3 métodos: Análisis de regresión lineal. Con los 15 sondajes disponibles y con una diferencia mínima de 1,5 mm y una $\mathrm{p}<0,05$; máx/mín diferencia entre el primer intervalo de tres meses y el último. Una modificación del método del punto final de Badersten 1987. Diferencia mínima de 1,5 mm entre periodos; la diferencia en NIC entre el final del estudio y baseline. Las localizaciones debían diferir al menos 2,5 mm.

Los resultados de este estudio sugerían que, a pesar del limitado número de pacientes e independientemente de la matemática usada (resultados más o menos similares para los 3 métodos), los pacientes con múltiples sondajes residuales $\geq 6 \mathrm{~mm}$ en la reevaluación (postratamiento causal inicial, no quirúrgico periodontal) tienen un mayor riesgo de presentar localizaciones con pérdida de inserción adicional que los pacientes con poco sondaje residual. En los pacientes identificados de este modo como más susceptibles, el sangrado persistente parece ser un indicador útil de futura pérdida de inserción a nivel de localización, estando justificado en estos casos, la indicación de cirugía periodontal.

En este estudio, sólo el sondaje $\geq 6 \mathrm{~mm}$ a los 3 meses (sondaje residual) mostró una asociación ES. Este dato es mucho mejor indicador que el sondaje pretratamiento. Los índices de placa no son, de acuerdo con los resultados obtenidos, buenos predictores de pérdida de inserción en pacientes mantenidos con profilaxis supragingival y/o subgingival.

\section{CONTRAINDICACIONES DEL TRATAMIENTO PERIODONTAL QUIRÚRGICO}

\section{El paciente con mal control de placa y no cooperante}

Los estudios de Axelsson Y Lindhe (1981) pusieron de manifiesto la importancia del óptimo control de placa como factor decisivo para el éxito del tratamiento periodontal. Un paciente que no coopere durante la fase de terapia relacionada con la causa no debe ser expuesto a un tratamiento periodontal quirúrgico $(7,8)$.

\section{El paciente fumador}

Numerosos estudios indican que el hábito de fumar afecta negativamente la cicatrización de las heridas quirúrgicas (13), podría no considerarse una contraindicación para el tratamiento quirúrgico periodontal. Sin embargo, se observa una menor reducción de la PB y menos mejoría en la inserción clínica en los fumadores que en no fumadores (14-16).

\section{El paciente transplantado y/o inmunodeprimido}

Los pacientes transplantados son en general pacientes medicados para prevenir el rechazo de los órganos transplantados. El fármaco de elección más utilizado actualmente es la Ciclosporina $A$, un potente inmunosupresor. Los efectos adversos que se observan en general tras el tratamiento con este fármaco aumentan el riesgo de hipertrofia gingival y de hiper- 
tensión. Además, a menudo son pacientes medicados con bloqueantes de los canales de calcio, por la hipertensión que se produce en receptores de los transplantes renales. Estos antihipertensivos también se asocian a hipertrofia gingival. Sin embargo, en los pacientes susceptibles y por la alta propensión a recidiva, debe estimularse el uso de una terapia periodontal conservadora intensa. En los transplantados medicados con inmunosupresores se recomienda la administración de profilaxis antibiótica antes de realizar cualquier tratamiento periodontal. El tratamiento quirúrgico debe, por otro lado, ser precedido de la administración de un colutorio de clorhexidina (CHX al 0,2\%) (17).

\section{El paciente con trastornos hemáticos}

Debe verificarse la naturaleza de estos trastornos. Los pacientes que padecen leucemia aguda, agranulocitosis y linfogranulomatosis no deben realizar cirugía periodontal. Las anemias de forma leve y compensadas no constituyen una contraindicación al tratamiento quirúrgico. Las formas más agudas o descompensadas pueden implicar disminución de la resistencia a la infección y mayor propensión al sangrado. En estos casos la cirugía periodontal debe posponerse hasta entrar en contacto con el médico del paciente (17).

\section{El paciente con trastornos endocrinos}

Diabetes mellitus: esta patología, muy prevalente en la población adulta, implica reducción de la resistencia a las infecciones, propensión al retraso en la cicatrización de las heridas y predisposición a la arteriosclerosis. Los pacientes bien compensados pueden ser subsidiarios de una cirugía periodontal, aunque se adopten precauciones para no perturbar los regímenes dietético y insulínico. En pacientes medicados con corticoides la función suprarrenal puede hallarse impedida en pacientes que reciben grandes dosis de estos fármacos, durante largos períodos de tiempo. Estas situaciones implican reducción de la resistencia al estrés físico y mental, y podría ser necesario alterar las dosis de estos fármacos durante una cirugía periodontal, en cuya situación hay que consultar al médico del paciente (17).

\section{El paciente con enfermedad cardiovascular}

Hipertensión arterial: por lo común no es obstáculo para la cirugía periodontal.
Angina de pecho: normalmente no prohibe la cirugía periodontal. Se recomienda utilizar una premedicación con sedantes y un anestésico local con bajo contenido de adrenalina.

Infarto de miocardio: estos pacientes no deben realizar cirugías periodontales dentro de los 6 meses ulteriores al infarto. Posteriormente solo deberán ser intervenidos en cooperación con su médico.

Tratamiento con anticoagulantes: estos pacientes son en general más propensos a las hemorragias, por lo que la cirugía periodontal debe programarse con el médico del paciente para determinar la necesidad de cambio de la medicación que está tomando.

Endocarditis reumática, cardiopatías congénitas e implantes cardíacos/vasculares: por la bacteriemia transitoria que se provoca tras RAR, y por esta sobrevive e involucra el riesgo de transmisión de bacterias a tejidos del corazón y a implantes cardíacos, el tratamiento quirúrgico debe ser precedido por el uso de colutorios antisépticos (CHX al 0,2\%) y por la prescripción y administración de un antibiótico adecuado en alta dosis, según las recomendaciones más actuales de la American Heart Association (ADA).

\section{TÉCNICAS QUIRÚRGICAS}

\section{Procedimientos de gingivectomía}

La gingivectomía, tal y como se emplea hoy en día fue descrita pro Goldman en 1951 (30). De este procedimiento se ilustra un caso (Fig. 3). En este caso el diagnóstico fue de erupción pasiva alterada, tipo 1 A según la Clasificación de Coslet de 1977 (31), en cuyo caso el tratamiento indicado es una gingivectomía.

La indicación más notoria para una gingivectomía es la presencia de bolsas supraalveolares profundas. La gingivectomía no se considera conveniente cuando la incisión lleva a la resección de toda la zona gingival. Esto sucede cuando el fondo de la bolsa está situado en la LMG o por debajo de ella. En tal caso, puede realizarse, como alternativa, una gingivectomía a bisel interno. En los últimos años, el desarrollo de métodos quirúrgicos con un campo de aplicación más amplio, han llevado a un uso menos frecuente de la gingivectomía en el tratamiento de la enfermedad periodontal. Además, esta técnica presenta como limitaciones no poder utilizarse para el tratamiento de localizaciones con lesiones infraóseas o cráteres óseos. 

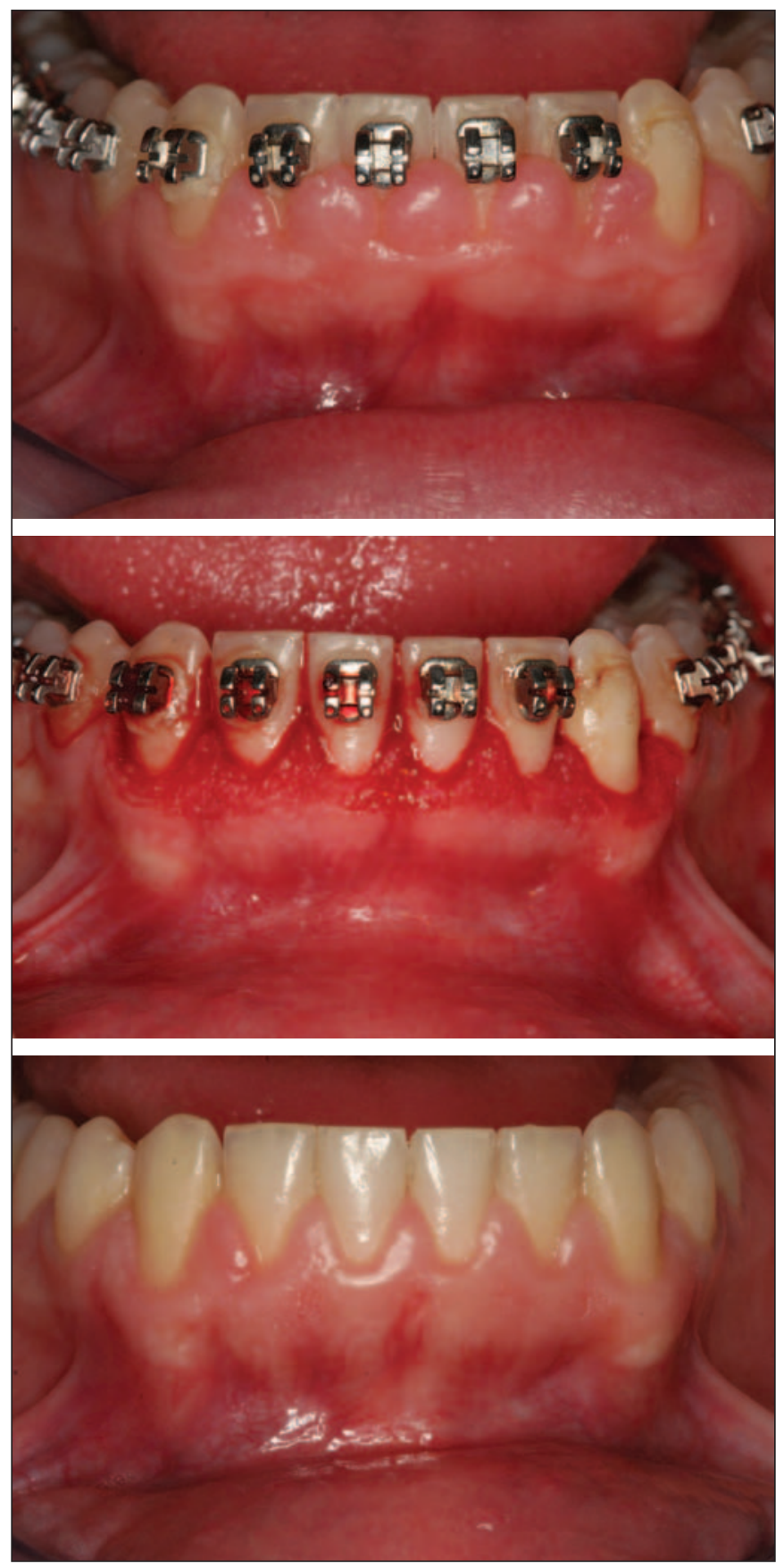

Fig. 3: Gingivectomía. Postoperatorio a los doce meses.

\section{Procedimientos con colgajo}

Un colgajo es la parte de encía y/o mucosa separada quirúrgicamente de los tejidos subyacentes para conseguir visibilidad y acceso al hueso y superficies radiculares, permitiendo además colocarlo en una situación diferente cuando hay problemas mucogingivales.
Las ventajas de la cirugía a colgajo incluyen:

- Preservación de la encía existente.

- Exposición del hueso marginal, gracias a lo cual es posible identificar la morfología de los defectos del hueso y tratarlos adecuadamente.

- Exposición de áreas de furcación, permitiendo la identificación del grado de afectación y relación entre el hueso y el diente.

- El procedimiento preserva el epitelio bucal y a menudo torna innecesario el uso de apósitos quirúrgicos.

- En comparación con la gingivectomía, el período postoperatorio por lo general ocasiona menos molestias al paciente.

\section{Clasificación de los colgajos periodontales}

Los colgajos periodontales se clasifican, de una forma didáctica, en cuanto a su espesor, su posición y su propósito.

1. Cuanto al espesor:

- Colgajo de espesor total o mucoperióstico: como el propio nombre indica, contienen todo el espesor del tejido, incluyendo el periostio. Está indicado en casos en los que se necesita cirugía ósea. Para llevarlo a cabo se realiza una incisión hacía el hueso y se levanta con un periostótomo todo el espesor del tejido, sin dejar periostio adherido.

- Colgajo de espesor parcial o mucoso: se eleva el epitelio y una capa de tejido conectivo subyacente. El hueso permanece cubierto por el periostio. Indicado en casos en los que no es necesario realizar cirugía ósea o se necesita una reposición del colgajo (apical, lateral, coronal).

2. Cuanto a la posición:

- Colgajos reposicionados o aposicionados: desplazados apicalmente (Fig. 4), coronalmente (Fig. 5) o lateralmente.

- Colgajos no reposicionados: colgajos palatinos o en el paladar, que debido a la ausencia de encía insertada no pueden ser reposicionados ni coronal, ni apical ni lateralmente en relación a su posición original (Fig. 6).

3. Cuanto al propósito:

- Ganancia de inserción.

- Eliminación de bolsas.

- Reparación mucogingival.

- Regeneración mucogingival (Fig. 6) 

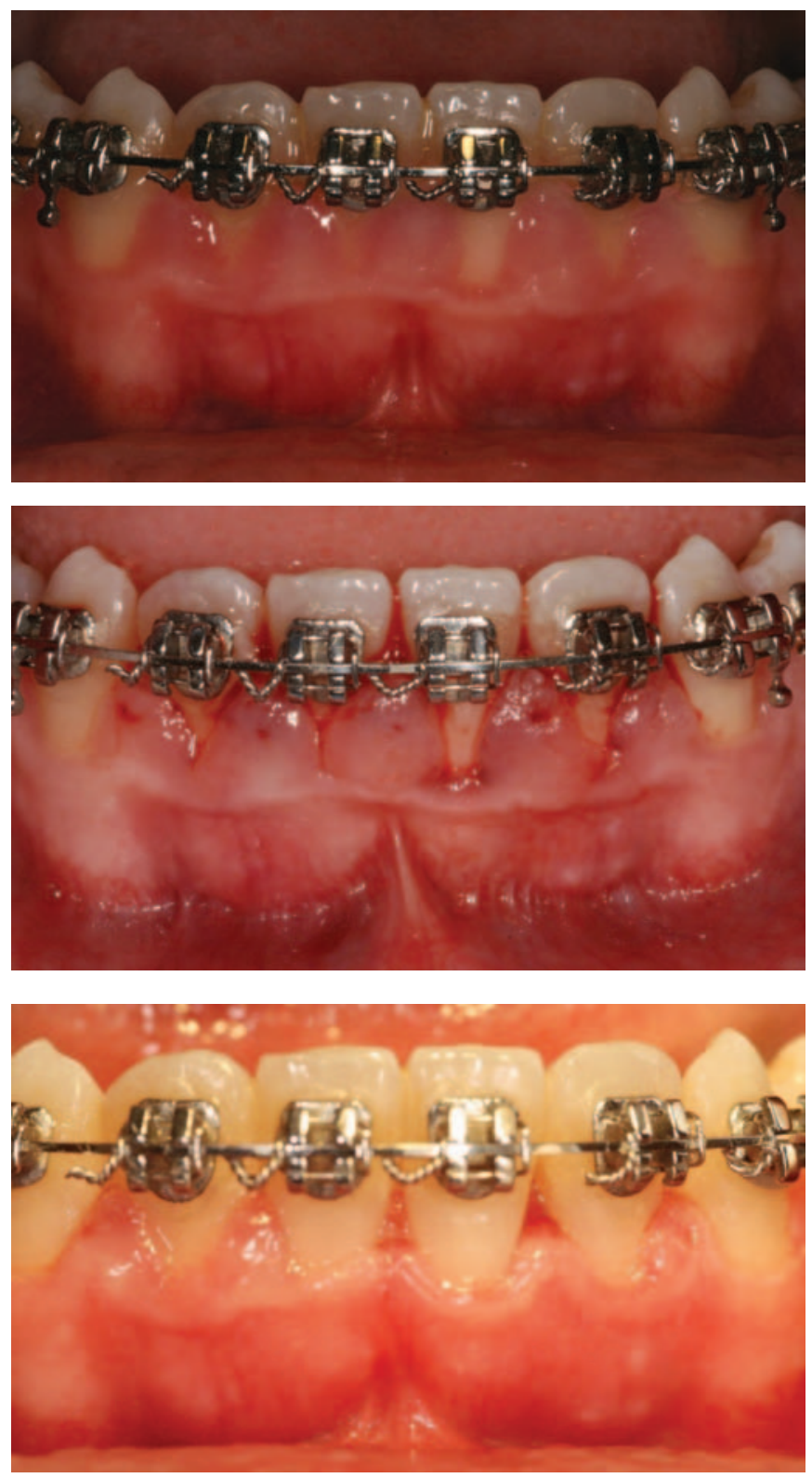

Las clasificaciones de distintas modalidades de colgajos utilizados en el tratamiento de la enfermedad periodontal muchas veces diferencian entre los métodos que involucran los tejidos marginales y aquellos que involucran el área mucogingival. Además, diferencian entre las variedades donde se elimina o reseca tejido y las que implican preservación/ reconstrucción tisular (colgajo de acceso para desbridamiento). Esas clasificaciones son más bien imprecisas, puesto que a menudo se combinan varias técnicas en el tratamiento de un paciente y porque no existe una relación definida entre las características de la enfermedad y la
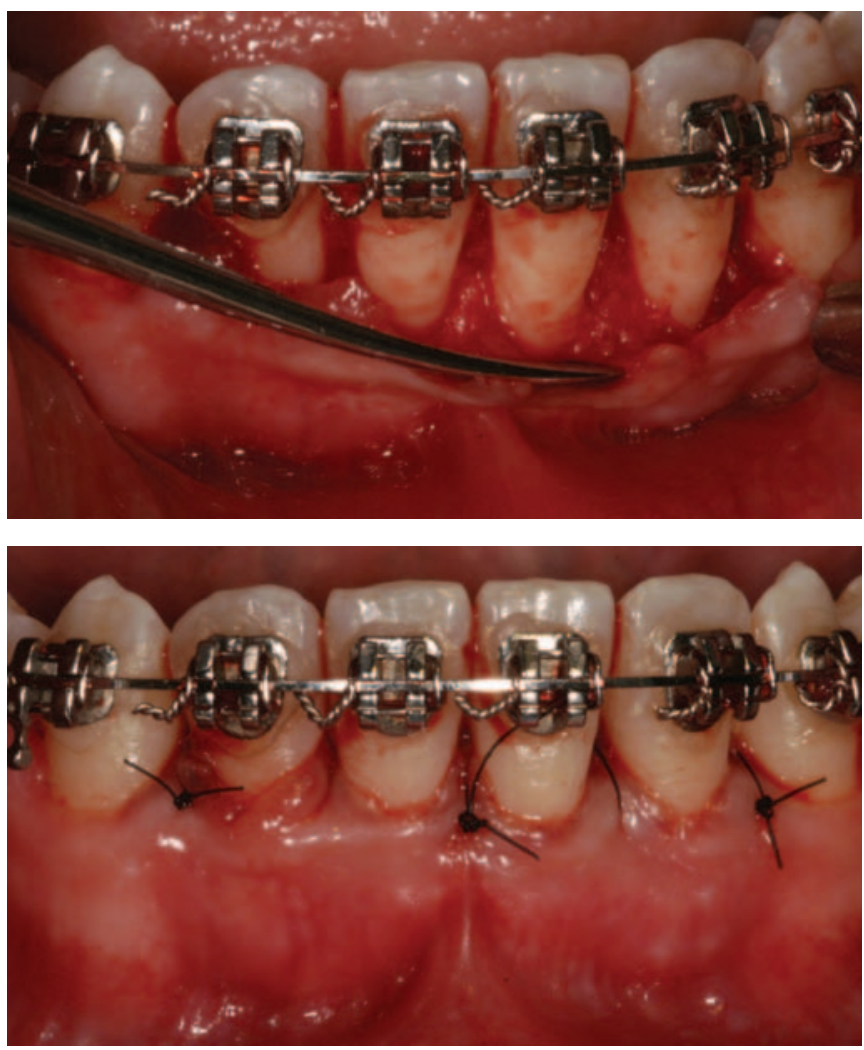

Fig. 4: Colgajo de reposición apical. Marcación de las bolsas. Para identificar la profundidad de bolsa se utiliza una sonda periodontal manual calibrada. Una vez evaluada la profundidad de bolsa se delinea una distancia equivalente sobre la cara gingival externa. La punta de la sonda se horizontaliza y se utiliza para producir un punto sangrante a nivel de la bolsa sondada. Resultado postoperatorio.

elección del método quirúrgico. Parece más adecuado discutir el tratamiento quirúrgico relativamente a cómo manejar el componente de tejidos blandos y el componente de tejidos duros de la bolsa periodontal en una localización específica (Fig. 6).

\section{Tipos de colgajos periodontales}

El primero en describir un colgajo de acceso a las superficies radiculares y a la cresta alveolar fue Neumann (1912), aunque sin el objetivo de eliminar la bolsa. En 


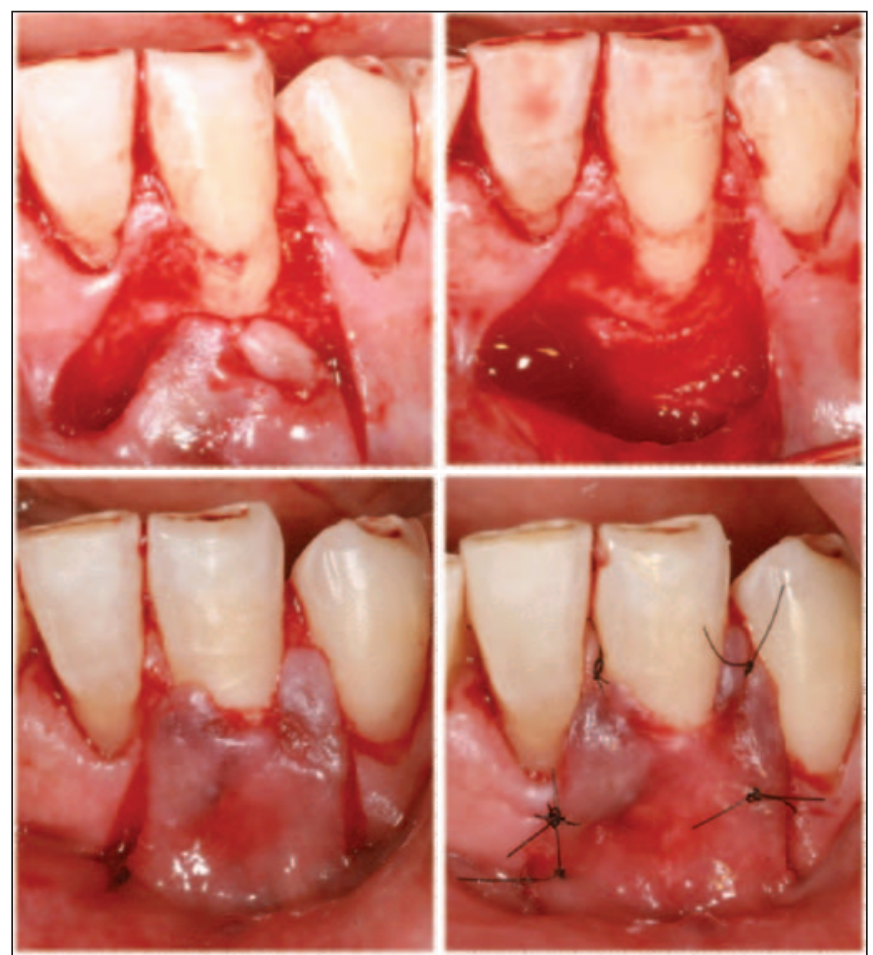

Fig. 5: Colgajo reposicionado coronalmente. Detalle del espesor parcial.

1920 el mismo autor describe el colgajo mucoperióstico. El primero en describir, por tanto, un colgajo con el objetivo de eliminar bolsas periodontales fue Widman en 1916 y describe, a su vez, la incisión a bisel interno.

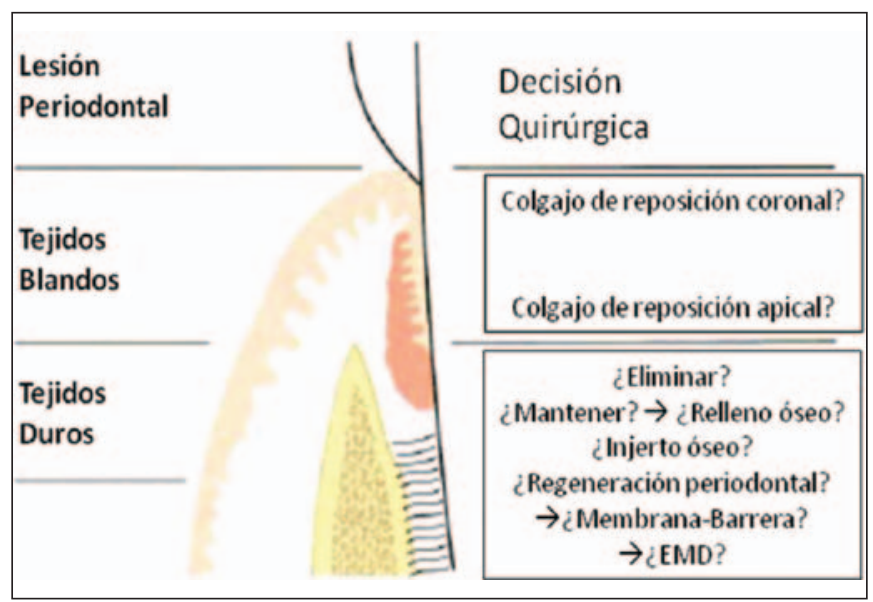

Fig. 6: Decisiones quirúrgicas: toma de decisiones sobre el tratamiento, con respecto a los componentes de tejidos duros y blandos de una bolsa periodontal. Adaptado de Lindhe J \& Karring T \& Lang NP. $4^{\text {th }}$ Edition. Blackwell Munksgaard (2004).
Zentler, en 1918 describe un colgajo mucoperióstico crevicular para la eliminación quirúrgica de bolsas periodontales. Pero el objetivo de eliminar las bolsas se cambia por la búsqueda de reinserción. Kirkland, en 1931 emplea el colgajo diseñado por Neuman, con la diferencia de que elimina el epitelio crevicular y el tejido conectivo. Diseña el denominado "curetaje abierto" que logra reducir la bolsa a partir de la recesión gingival y de reinserción epitelial.

Pero sin duda, la técnica más adecuada para la reinserción es el procedimiento denominado "Colgajo de Widman Modificado", descrito por Oestman en 1930. Ésta es una técnica de colgajo mucoperióstico a bisel interno cuyo objetivo no es la eliminación de la bolsa, ni exposición del hueso interproximal (como realiza Widman de acuerdo con su técnica original). Esta técnica era inicialmente sólo empleada para casos de enfermedades periodontales avanzadas o en zonas estéticas, pero ha ido siendo modificada por muchos autores y busca la reinserción mediante el curetaje subgingival.

\section{Colgajo de Widman modificado (Ramfjord) (24)}

Esta técnica está indicada en el tratamiento de todo tipo de bolsas periodontales, en cualquier localización de la boca. Además, las mayores ventajas se observan en el tratamiento de bolsas profundas, defectos infraóseos y cuando queremos que se produzca una mínima recesión (sector anterosuperior).

La técnica quirúrgica fue descrita con mayor precisión en 1914. Debe realizarse 2 a 3 meses tras el tratamiento periodontal causal:

1. Se realiza una primera incisión paralela al eje longitudinal de los dientes, localizada al menos a medio milímetro del margen gingival con el fin de eliminar el epitelio crevicular, con un diseño festoneado y con o sin incisiones de descarga verticales.

2. Posteriormente se eleva un colgajo mucoperióstico, necesario para permitir el acceso a las superficies radiculares y al hueso interproximal.

3. Se realiza una segunda incisión a hueso, a nivel intracrevicular.

4. La tercera incisión se hace con un instrumento afilado, a nivel de la cresta alveolar y eliminará el rodete de tejido gingival separado del colgajo. Para ello, nos ayudaremos de cuerdas.

5. Las superficies radiculares deben ser alisadas y el tejido de granulación despegado. Los colgajos deben readaptarse al hueso subyacente y coaptar a 
nivel interproximal. Está indicado realizar presión con una gasa humedecida. En este punto podría retocarse el colgajo o el hueso del proceso alveolar si la adaptación no fuese buena.

6. Se suturan los colgajos y se aplica pomada de Acromicina sobre las suturas y se utiliza cemento quirúrgico.

7. A la semana se retiran las suturas y el cemento quirúrgico y se pulen los dientes, reforzando las instrucciones de higiene oral y estableciendo un protocolo de mantenimiento cada 3 meses.

Este tipo de colgajo establece una adaptación postoperatoria a la superficie radicular con tejido conectivo y epitelio sanos. Además, se genera un epitelio largo de unión, que protege frente a la penetración bacteriana. La readaptación y la reinserción debe ser tan buena a nivel vestibular como interproximal.

El objetivo de este tipo de colgajos es la máxima cicatrización y reinserción, con mínima pérdida de tejido periodontal y lo consigue a través de la formación de un epitelio largo de unión y una buena adaptación del conectivo con o sin reinserción de las fibras y con o sin regeneración ósea.

Presenta, por otro lado, la desventaja de obtener una arquitectura gingival plana o negativa a nivel interproximal tras la cirugía, pero que se va recuperando e incluso, a largo plazo, muestra menor recesión a este nivel que empleando otras técnicas quirúrgicas de eliminación de bolsa (24).

El exhaustivo control de placa, tanto por parte del paciente como por el profesional son fundamentales para el éxito del tratamiento. La adecuada cicatrización y la prevención de la extensión apical de la placa son aspectos fundamentales.

\section{Colgajo de reposición apical (Friedman) (21)}

Friedman utiliza una técnica quirúrgica refinada. Los objetivos continúan siendo los mismos: eliminar bolsas, hacer cirugía ósea para tener una arquitectura ósea positiva e dejar el hueso denudado para ganar encía queratinizada.

En esta época los objetivos de la cirugía mucogingival eran los siguientes:

- La bolsa debería ser eliminada y una cantidad funcionalmente adecuada de encía debería existir postoperatoriamente.
- La encía marginal y la papila interproximal no deberían ser retractables cuando sujetas a tensión excesiva, como el tirón de los músculos, transmitido a la mucosa alveolar y al freno.

- Debería existir suficiente profundidad de vestíbulo, constante, con una zona funcionalmente adecuada de encía insertada.

Friedman publica en este año la descripción de una técnica con un diseño de colgajo para eliminación de bolsas (disminución de PS) que aún hoy se utiliza. En esta publicación describe los objetivos de la técnica, bien como sus indicaciones, ventajas y desventajas, la metodología del examen clínico y planeamiento prequirúrgico y la técnica, paso a paso.

Según lo descrito, el colgajo debe biselarse al máximo para producir un complejo gingival tan delgado como posible. Las incisiones verticales se deben extender de la encía a la mucosa alveolar, para permitir facilidad de acceso al área quirúrgica y para proporcionar flexibilidad durante la cirugía. Además, el colgajo debe suturarse de forma precisa, al nivel de la cresta alveolar, suturando las incisiones verticales y también en interproximal (cicatrización por primera intención).

Las indicaciones de la técnica son:

- El ARF (Colgajo reposicionado apicalmente) está indicado en áreas donde la base de la bolsa es próxima o apical a la LMG y donde permanezca suficiente cantidad de encía tras el adelgazamiento, para constituir un colgajo mucoperióstico que se pueda manipular fácilmente.

- El concepto de ARF para eliminación de bolsas va unido a $\mathrm{Q}^{\circ}$ ósea. Este autor aboga todo el tiempo que para la cirugía ósea para conseguir una arquitectura ósea positiva.

Para seleccionar los procedimientos terapéuticos (tipo de cirugía) particularmente indicados y que cumplen con los objetivos indicados por el autor, el examinador debe tener:

1. La capacidad de visualizar donde está la base de la bolsa en relación a la LMG.

2. En qué medida el hueso se reabsorbió.

3. Cuál es el patrón de la resorción ósea, y

4. Dónde está el nivel de hueso relativamente a los tejidos blandos.

Cuanto a la técnica, consiste de los siguientes pasos: 
1. Raspado y alisado radicular y ajuste oclusal previos a la cirugía.

2. La primera incisión es horizontal. Esta incisión crea el bisel interno y se realiza para producir un colgajo más fino (delgado). Idealmente debería ser festoneada para que en IP se pudiera suturar y dejar cubierto todo el hueso. La localización de la primera incisión dependerá de: la profundidad de la bolsa, el espesor de la encía, la cantidad total de encía existente preoperatoriamente, la extensión de encía que queremos tener postoperatoriamente.

3. Las incisiones verticales se realizan en mesial y distal al área quirúrgica.

4. Se eleva el colgajo, observándose que este es fino, con sus partes adelgazadas.

5. Se elimina la encía de la zona 2 , se levanta el colgajo y se expone el hueso.

6. Contorneado óseo: ranuras ID se establecen y los niveles de hueso se confinan a una serie de curvas parabólicas.

7. Reposición del colgajo a nivel apical en relación a su posición inicial de forma a cubrir la cresta alveolar vestibular. No se debe dejar el hueso expuesto y para eso hay que festonear y no hacer una incisión recta que dejaría las crestas IP expuestas (en todo caso si el hueso se deja expuesto es para ganar más encía queratinizada). Sólo así se consigue cicatrización por primera intención. Con el colgajo palatino es distinto: como no se puede reposicionar apicalmente el colgajo. Se elimina la encía en exceso a la vez que se adelgaza el colgajo y se realiza cirugía ósea para poder eliminar bolsas y se realiza cirugía ósea para obtener un contorneado fisiológico.

Cuanto a los cuidados postoperatorios, se puede utilizar cemento quirúrgico para cubrir el área.

Si se sutura a nivel de la cresta alveolar, aproximadamente $2 \mathrm{~mm}$ de tejido de granulación va a ser añadido al colgajo y se diferenciará en encía. Durante la cicatrización, la granulación se adhiere al cemento de la raíz y forma nuevas fibras gingivales.

A la semana, pequeñas áreas de hueso previamente expuesto se cubren de tejido de granulación. A las 2 semanas estas áreas han cicatrizado por $2^{a}$ intención y están casi completamente epitelizadas. A las 3 semanas está completa la cicatrización.

Las ventajas de este procedimiento son:

- La cicatrización es esencialmente por primera intención y por eso es más rápida y con menos dolor postoperatorio.
- Se proporciona una cobertura máxima del hueso por tejido viable, previniendo secuestros macroscópicos y probablemente minimizando pérdida permanente de hueso alveolar de la cresta.

- La cantidad de encía postoperatoria puede controlarse con precisión.

- Especialmente útil cuando uno o dos dientes están afectados porque el colgajo puede confinarse a las áreas afectadas.

- La manutención del complejo mucogingival y el traslado hacia apical permite crear una unidad funcional adecuada para profundizar el vestíbulo y reposicionar el frenillo utilizando tejido maduro.

- Es una cirugía controlada con una técnica refinada (festoneado, eliminación de bolsas y sutura).

Por otro lado, resulta más difícil de ejecutar técnicamente porque el colgajo debe ser muy bien suturado y la porción gingival tiene que estar muy bien adelgazada sino la encía cuando cicatrice va a ser muy gruesa. Además, en presencia de una menor cantidad de encía preoperatoriamente es difícil manejar y suturar el colgajo. El acceso difícil en zonas de $2^{\circ}$ y $3^{\mathrm{er}}$ molares inferiores, donde tenemos un vestíbulo corto dificulta el procedimiento. En estos casos, el "doble colgajo" de Ochsenbein parece ser el más indicado (introduce el concepto de que dejando el periostio en vestibular se produce menos dolor y a partir de este concepto surge el CRA a espesor parcial, para ganar profundidad de vestíbulo y encía adherida con denudación ósea, importante en maxilar, pero sobretodo en mandíbula, donde no hay profundidad de vestíbulo).

\section{Cicatrización de los tejidos periodontales}

Resulta importante comprender los fenómenos que ocurren durante la cicatrización de los tejidos en los diferentes procedimientos quirúrgicos periodontales.

\section{Gingivectomía}

La epitelización de la herida se completa 7-14 tras la gingivectomía. En las semanas siguientes se forma una nueva unidad dentogingival. Los fibroblastos de los tejidos supraalveolar adyacente y la superficie dental proliferan (18) y se deposita nuevo tejido conectivo. Si la cicatrización ocurre próxima a una superficie dental libre de placa se formará una nueva unidad de encía libre normal (19). La altura de la unidad recién formada puede variar, no solo en distintas localizaciones de la boca, como en una u otra superficie de un mismo 
diente, debido esencialmente a factores anatómicos. El restablecimiento de una nueva unidad de encía libre, por crecimiento de nuevo tejido hacia coronal de la línea de incisión de la gingivectomía implica que las localizaciones denominadas "bolsas cero" se ven solo ocasionalmente tras una gingivectomía. La cicatrización completa se da en 4-5 semanas, aunque a los 14 días la superficie de la encía puede aparecer cicatrizada a la inspección visual clínica (20). En el postoperatorio puede ocurrir un remodelado menor de la cresta ósea alveolar (Fig. 7).

\section{Colgajo de reposición apical}

Con el restablecimiento de los contornos fisiológicos, el colgajo constituirá los nuevos niveles de inserción en el nivel suturado. La cicatrización ocurrirá principalmente por primera intención, en especial en las áreas donde se obtuvo cubrimiento correcto del hueso alveolar con tejidos blandos (21). Durante la fase inicial de cicatrización, casi siempre ocurre una reabsorción ósea de grado variado en el área de la cresta del hueso alveolar (22). La magnitud de la reducción de la altura de hueso alveolar, resultante de esta resorción, está relacionada con el espesor de hueso en cada localización específica (23). Durante las fases de regeneración y maduración tisular, se forma una nueva unidad dentogingival por crecimiento coronal del tejido conectivo. Este crecimiento ocurre de modo similar al que caracteriza la cicatrización tras una gingivectomía (Fig. 8).

\section{Colgajo de Widman Modificado (MWF)}

Si se trata de una localización con una lesión infraósea profunda, puede ocurrir reparación ósea dentro de los

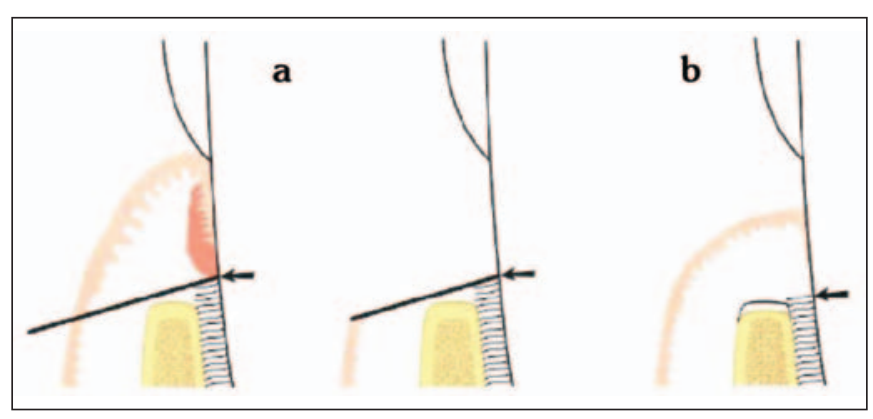

Fig. 7: Cambios dimensionales producidos tras una gingivectomía. a) Dimensiones preoperatorias. b) dimensiones tras una adecuada cicatrización. Tras este procedimiento se produce una reabsorción ósea menor en la cresta alveolar y cierta pérdida de inserción de tejido conectivo.

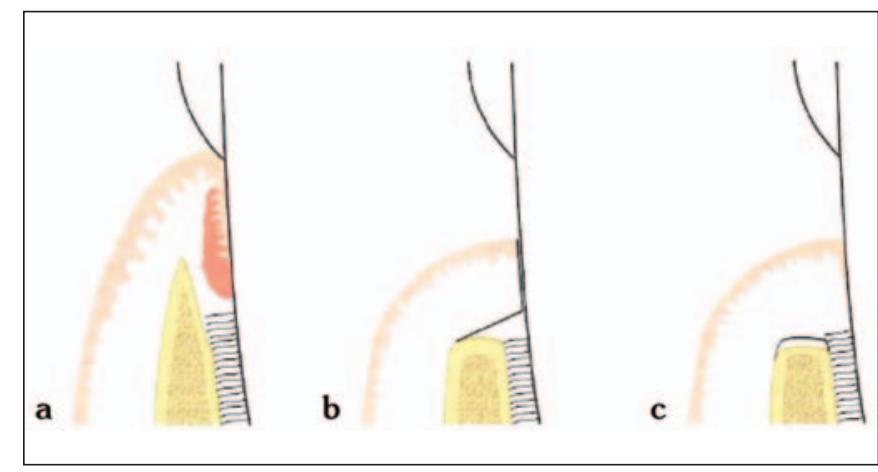

Fig. 8: Cambios dimensionales producidos en un Colgajo de reposición apical. a) Dimensiones preoperatorias. b) Recontorneado óseo. c) Dimensiones tras cicatrización.

límites de la lesión (24-26). Sin embargo, también se observa reabsorción ósea de la cresta. La cantidad de relleno óseo obtenida dependerá de varios factores: la anatomía del defecto óseo y de la cantidad de reabsorción ósea de la cresta, la extensión de la inflamación crónica. Entre el tejido óseo regenerado y la superficie radicular se encuentra siempre interpuesto un epitelio largo de unión $(27,28)$. Las células apicales del epitelio de unión recién formado se encuentran a un nivel de la raíz que coincide estrechamente con el nivel de inserción postoperatorio. En la fase de cicatrización tras un MWF se produce retracción de los tejidos blandos, aunque el mayor desplazamiento apical en la posición del margen de estos se observa durante los primeros 6 meses ulteriores al tratamiento quirúrgico (28). Esta retracción dura en general más de un año. Entre los factores que influyen en el grado de retracción gingival se destacan, además del periodo de remodelación de estos tejidos, la altura inicial y el espesor del tejido supracrestal del colgajo y la cantidad de reabsorción de hueso de la cresta (Fig. 9).

\section{Procedimientos Regenerativos}

En la década de 1980 el tratamiento de las bolsas periodontales adquirió una nueva dimensión, cuando se demostró que con un manejo quirúrgico específico se puede obtener una cantidad significativa de nueva inserción de tejido conectivo tras el tratamiento quirúrgico $(32,33)$.

Obtener la regeneración periodontal siempre ha sido un gran desafío y en el transcurso de los años se utilizaron varios abordajes. No obstante, en esta revisión no abordamos los diversos procedimientos regenerativos para el tratamiento de defectos periodontales, así como la base biológica de la regeneración periodontal. 


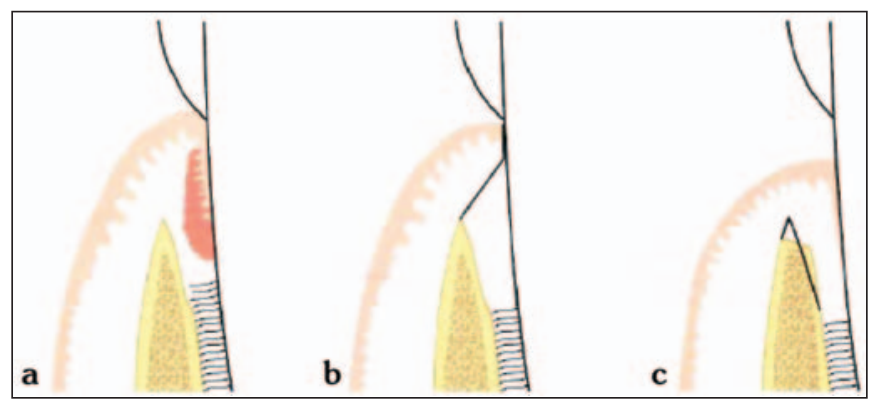

Fig. 9: Cambios dimensionales en un Colgajo de Widman Modificado. a) Dimensiones preoperatorias. b) La cirugía se completa con la reubicación del colgajo mucoperióstico lo más próximo posible de su posición original prequirúrgica. c) Dimensiones tras la cicatrización.

\section{Procedimientos de CUÑa distal}

El tratamiento de las bolsas periodontales en la superficie distal de los molares posteriores se complica por la presencia de tejidos bulbosos sobre la tuberosidad por una zona retromolar prominente. El abordaje más directo para la eliminación de la bolsa en esos casos y tratándose del maxilar superior es la gingivectomía (Fig. 10).

Sin embrago, cuando existe una cantidad limitada o nula de tejido queratinizado o en casos en los que se ha diagnosticado un defecto óseo angular, el tejido prominente debe ser reducido en sus dimensiones, en vez de eliminarlo de todo. Para ello podemos realizar un procedimiento de cuña distal (34). Esta técnica facilita el acceso al defecto óseo y posibilita preservar cantidad suficiente de encía y mucosa para obtener el recubrimiento con tejidos blandos.

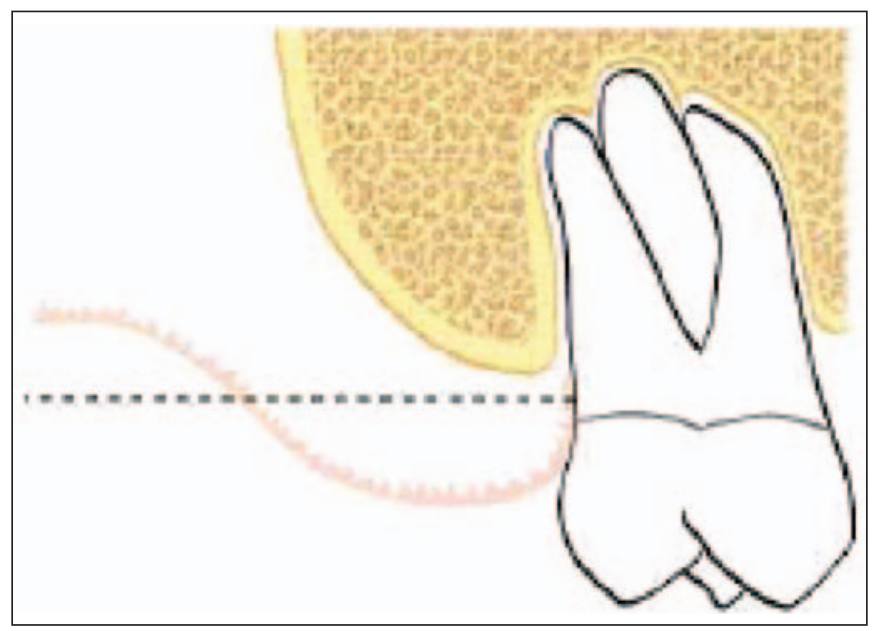

Fig. 10: Procedimiento de una cuña distal. Para eliminar una bolsa periodontal en un molar superior se realiza una incisión simple para gingivectomía (línea de puntos).

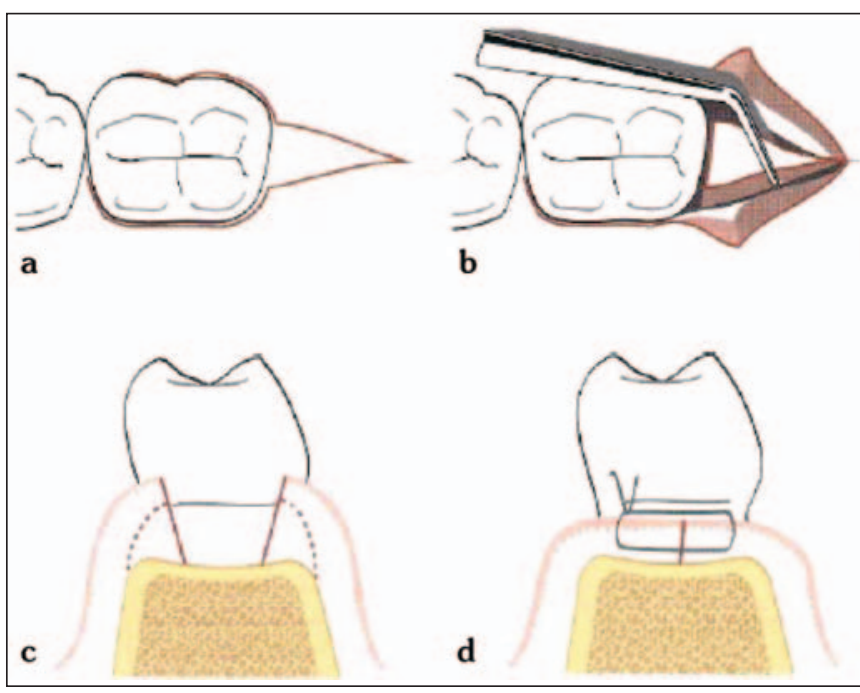

Fig. 11: a) Incisiones verticales por vestibular y por lingual a través de la zona retromolar, para formar un triángulo detrás de un molar inferior. b) La cuña de tejidos en forma de triángulo es desecada del hueso subyacente y extirpada. c) El espesor de las paredes de los colgajos se reduce mediante incisiones socavantes. d) Sutura de los colgajos.

El procedimiento original puede ser modificado conforme los requerimientos individuales. Todas las modificaciones de la técnica tienen como objetivo eliminar la bolsa profunda y obtener un recubrimiento mucoso para el periodonto remanente (Fig. 12).

\section{Cirugía Ósea}

Los principios de la cirugía ósea aplicados al tratamiento quirúrgico periodontal fueron primeramente descritos por Schluger (1949) y Goldman (1950). Estos autores señalaron que la pérdida de hueso alveolar ocasionada por la enfermedad periodontal suele resultar en perdida ósea irregular. Para estos autores la eliminación de las bolsas periodontales debía combinarse con cirugía ósea y con la eliminación de cráteres y defectos angulares óseos para establecer y mantener bolsas poco profundas y un contorno gingival óptimo tras la cirugía (35).

\section{CONCLUSIONES}

El tratamiento quirúrgico de la enfermedad periodontal cumple esencialmente dos propósitos: por un lado, crea la accesibilidad para el correcto desbridamiento profesional de las superficies radiculares desbridadas; por otro, establece una morfología gingival que facilita el autocontrol de placa y mejora la preservación de sus dientes a largo plazo. 


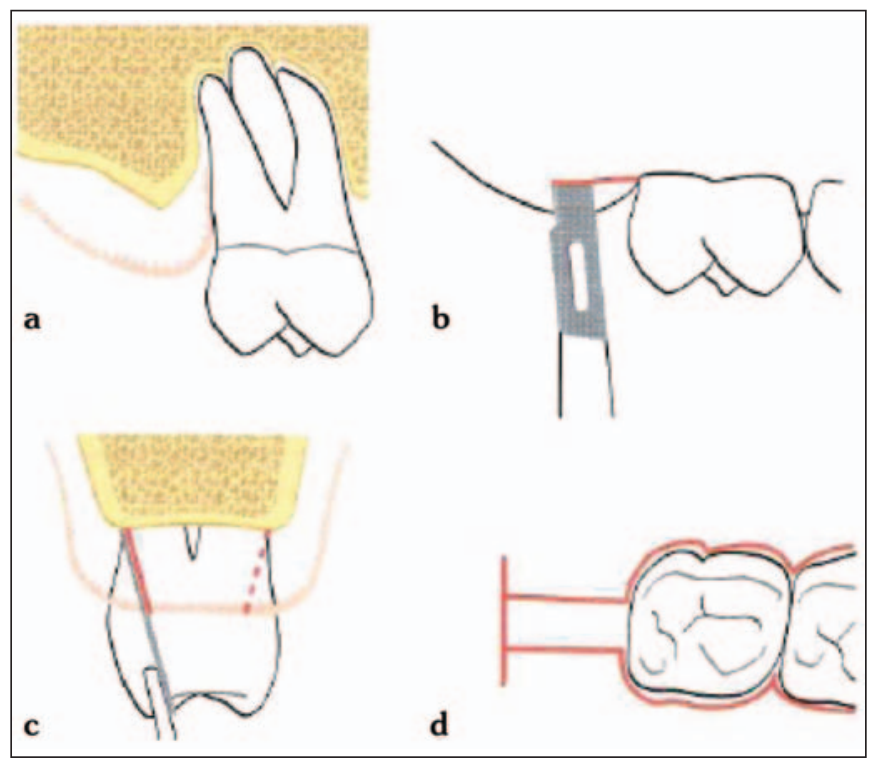

Fig. 12: Procedimiento de cuña distal modificado.

El tratamiento periodontal quirúrgico no solo está indicado en situaciones como en la eliminación de bolsas periodontales profundas. Tras tratamiento periodontal no quirúrgico y reevaluación, también puede
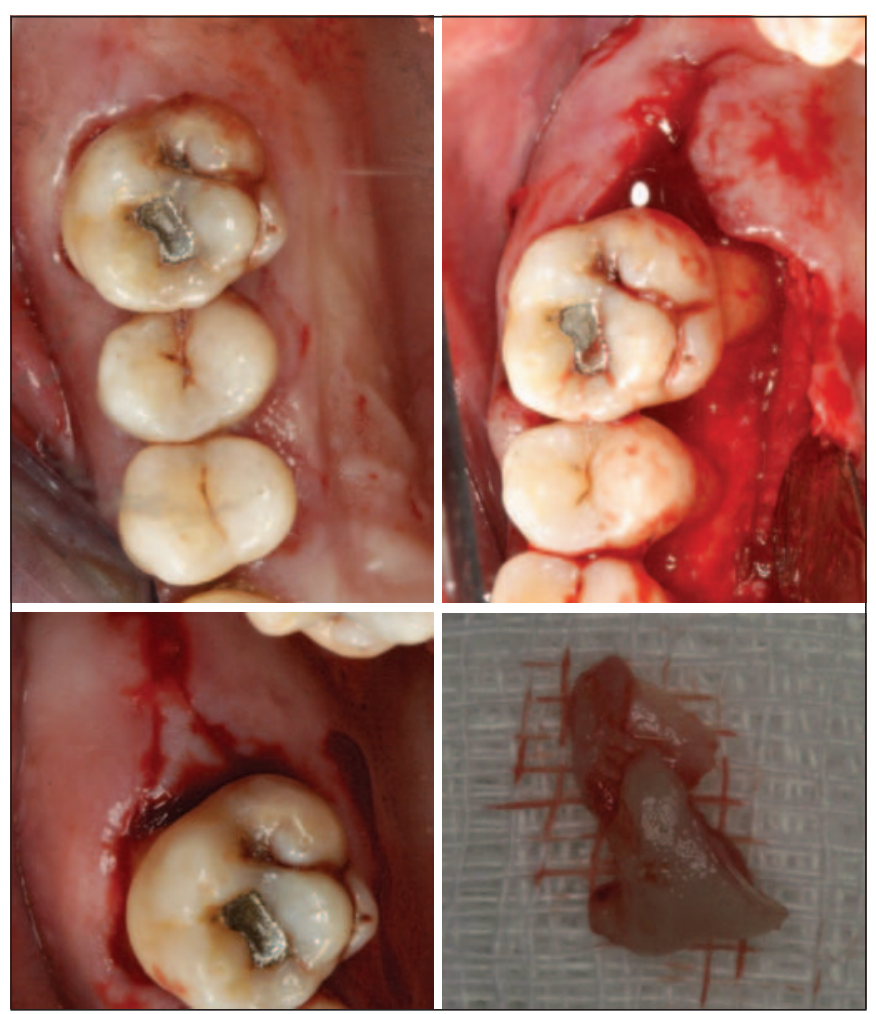

Fig. 13: Procedimiento de cuña distal en la región de la tuberosidad. indicarse en el tratamiento de en defectos óseos de forma a restablecer el contorno óseo fisiológico del hueso alveolar; o en problemas mucogingivales, bien sea por razones de tipo estético o cosmético o por hipersensibilidad, recesiones de la encía marginal o caries de cuello (lesiones de abrasión o atrición). Otras indicaciones incluyen el desbridamiento de abscesos periodontales agudos. La tendencia a la recidiva, problemas de tipo estético, la posibilidad de aumentar la tendencia a la caries y la sensibilidad dentaria son algunos de los inconvenientes del tratamiento periodontal quirúrgico.

\section{BIBLIOGRAFÍA}

1. Lindhe J, Nyman S. The effect of plaque control and surgical pocket elimination on the establishment and maintenance of periodontal health. A longitudinal study of periodontal therapy in cases of advanced disease. Journal of Clin Periodontol 1975;2:67-79.

2. Badersten A, Nilvéus R, Egelberg J. Effect of non-surgical periodontal therapy (IV). Operator variability. J Clin Periodontol. 1985 Mar;12(3):190-200.

3. Lindhe J, Westfelt E, Nyman S, Socransky SS, Heijl L, Bratthall G. Healing following surgical/non-surgical treatment of periodontal disease. Journal of Clin Periodontol 1982;9:115-28.

4. Listgarten MA, Mao R, Robinson PJ. Periodontal probing and the relationship of the probe of the tip to periodontal tissues. J Periodontol 1976;47:51 1-13.

5. Armitage GC, Svanberg GK, Löe H. Microscopic evaluation of clinical measurements of connective tissue attachment level. Journal of Clin Periodontol 1977;4: 173-90.

6. Listgarten MA. Periodontal probing:What does it mean? Journal of Clin Periodontol 1980;7:165-176.

7. Axelsson P, Lindhe J. The significance of maintenance care in the treatment of periodontal disease. J Clin Periodontol 1981 Aug;8(4):281-94.

8. Axelsson P, Lindhe J. Effect of controlled oral hygiene procedures on caries and periodontal disease in adults. Results after 6 years.J Clin Periodontol 1981 Jun;8(3): $239-48$.

9. Claffey N, Egelberg J. Clinical indicators of probing attachment loss following initial periodontal treatment in advanced periodontitis patients. J Clin Periodontol. 1995 Sep;22(9):690-6. 
10. Waerhaug, J. Healing of the dentoepithelial junction following subgingival plaque control. II. As observed on extracted teeth. Journal of Periodontology 1978;49: 119-34.

11. Caffesse RG, Sweeney PL, Smith BA. Scalling and root planning with and without periodontal flap surgery. J Clin Periodontol 1986;13:205-10.

12. Badersten A, Nilveus R, Egelberg J. Effect of non-surgical periodontal therapy. I. Moderately advanced periodontitis. J Clin Periodontol 1981;8:57-72.

13. Siana JE, Rex S, Gottrup, F. The effect of cigarette smoking on wound healing. Scandinavian Journal of Plastic and Reconstructive Surgery and Hand Surgery 1989;23:207-9.

14. Preber, H. \& Bergstrom, J. Effect of cigarette smoking on periodontal healing following surgical therapy Journal of Clinical Periodontology 1990;17:324-8.

15. Ah MKB, Johnson GK, Kaldhal WB et al.The effect of smoking on the response to periodontal therapy. J Clin Periodontol 1994;21:91-7.

16. Scabbia A, Cho KS, Sigurdsson TJ, Kim CK, Trombelli L. Cigarette smoking negatively affects healing response following flap debridement surgery. Journal of Periodontology 2001;72:43-9.

17. Wennström JL, Heijl L, Lidhe J. Periodontal Surgery: Access Surgery. In: Lindhe J \& Karring T \& Lang NP. ${ }^{\text {th }}$ Edition. Blackwell Munksgaard. 2004.

18. Waerhaug J. Microscopic demonstration of tissue reaction incident to removal of subgingival calculus. Journal of Periodontology 1955;26:26-9.

19. Hamp SE, Rosling B, Lindhe, J. Effect of chlorhexidine on gingival wound healing in the dog. Ahistometric study. Journal of Clinical Periodontology 1975;2:143-52.

20. Ramfjord SE, Engler WO, Hiniker JJ. A radioautographic study of healing following simple gingivectomy II. The connective tissue. Journal of Periodontology 1966;37: 179-89.

21. Friedman N. The apically repositioned flap. Journal of periodontology. 1962;33:328-40.

22. Ramfjord SF, Costich ER. Healing after exposure of periosteum on the alveolar process. Journal of periodontology. $1968 \mathrm{Jul} ; 39(4)$ :199-207.

23. Karring T, Cumming BR, Oliver RC, Loe H. The origin of granulation tissue and its impact on postoperative results of mucogingival surgery. Journal of periodontology. 1975 Oct;46(10):577-85.
24. Ramfjord SP. Present status of the modified Widman flap procedure. Journal of periodontology. 1977 Sep;48(9): 558-65.

25. Rosling B,Nyman S, Lindhe J.The effect of systemic plaque control on bone regeneration in infrabony pockets. Journal of Clinical Periodontology 1976a;3:38-53.

26. Rosling B, Nyman S, Lindhe J, Jern B. The healing potential of the periodontal tissue following different techniques of periodontal surgery in plaque-free dentitions. A 2- year clinical study. Journal of Clinical Peridontology 1976b;3:233-55.

27. Caton, J,Nyman, S. \& Zander, H. Histometric evaluation of periodontal surgery II. Connective tissue attachment levels after four regenerative procedures. Journal of Clinical Periodontology 1980;7:224-31.

28. Caton, J.G. \& Zander, H.A.. Osseous repair of an infrabony pocket without new attachment of connective tissue Journal of Clinical Periodontology 1976;3:54-8.

29. Lindhe, J,Socransky, S.S,Nyman, S. \& Westfelt, E. Dimensional alteration of the periodontal tissues following therapy. International Journal of Periodontics \& Restorative Dentistry 1987;7(2):9-22.

30. Goldman HM. Gingivectomy. Oral Surgery, Oral Medicine and Oral Pathology 1951;4:1136-57.

31. Coslet JG. Alpha Omega. 1977;3:24-8.

32. Nyman S, Lindhe J, Karring T, Rylander H. New attachment following surgical treatment of human periodontal disease. Journal of Clinical Periodontology 1982;9:290-6.

33. Bowers GM,Chadroff B, Carnevale R, Mellonig JT, Corio R, Emerson J, Stevens M, Romberg E. Histologic evaluation of new human attachment apparatus formation in humans, Part III. Journal of Periodontology 1989;60: 683-93.

34. Robinson RE. The distal wedge operation. Periodontics 1966;4:256-64.

35. Schluger, S. Osseous resection - a basic principle in periodontal surgery? Oral Surgery, Oral Medicine and Oral Pathology 1949;2:316-25.

\section{CORRESPONDENCIA}

\author{
Rita Matos Cruz \\ C/ Irún, 7, $4^{\circ} \mathrm{B}$ \\ 28008 Madrid \\ España
}

E-mail:ritamatoscruz@gmail.com 